\title{
Sensor fluorescente baseado em complexo de lantanídeo imobilizado em nanopartículas de sílica para a determinação de oxigênio dissolvido em água
}

\author{
Caroline Ap. D. Rampazo*, Rafael D.L. Gaspar, Rafael S. Fernandes e Ivo M. Raimundo Jr.
}

\section{Resumo}

As nanopartículas de sílica ( $\left.\mathrm{NP}-\mathrm{SiO}_{2}\right)$ têm ocupado uma posição de destaque na área da química devido as suas diversas aplicações dentro do ramo industrial e científico, como por exemplo, pigmentos, carreadores de fármacos e ativos, sensores e isoladores térmicos. A fim de se seguir dentro desta mesma linha de pesquisa, neste trabalho foi desenvolvido um nanosensor fluorescente baseado na imobilização do complexo de lantanídeo $\left[\mathrm{Tb}(\mathrm{pfba})_{3}\right] \cdot \mathrm{H}_{2} \mathrm{O}$ em nanopartículas constituídas de sílica para uma futura determinação de oxigênio dissolvido em água. As nanopartículas foram sintetizadas via método Stöber, o qual envolve a hidrólise e a condensação de tetraetilortosilicato (TEOS) em etanol na presença de hidróxido de amônio, e também caracterizadas quanto ao seu diâmetro médio $\left(D_{m}\right)$, índice de polidispersidade (PDI) por espalhamento dinâmico de luz (DLS), e infravermelho (IR). Os resultados mostraram a obtenção de nanosensores com $D_{m}$ em torno de $101,3 \mathrm{~nm}$ e PDI menor que 0,1. Os espectros obtidos pela radiação infravermelha incidida na amostra mostraram que há a formação de nanopartículas de sílica devido ao aparecimento de modos vibracionais em 1057, 799 e $470 \mathrm{~cm}^{-1}$ que são características deste tipo de partícula.
Palavras-chave:
Nanopartículas
de silica,
nanosensor
fluorescente,
oxigênio.

\section{Introdução ${ }^{1}$}

Nos dias de hoje, muito interesse tem sido voltado para a pesquisa de nanomateriais e desenvolvimento de novas nanotecnologias. Desta forma, o objetivo central do trabalho foi desenvolver um nanosensor óptico a base de sílica para a detecção de oxigênio dissolvido em água. $O$ método utilizado foi o de Stöber (baseado no processo sol-gel que possui inúmeras etapas, como hidrólise e condensação, gelificação, envelhecimento e secagem), que permite obter partículas esféricas com tamanho uniforme. Para o desenvolvimento deste tipo de sensor óptico, uma possível alternativa é a imobilização de materiais fluoróforos em sua estrutura, como por exemplo, complexos de lantanídeo. Estes complexos possuem características muito favoráveis para essa finalidade, como bandas de excitação e emissão na região do visível ou infravermelho, alto brilho, alta sensibilidade, fotoestabilidade e tempos longos de decaimento.

\section{Resultados e Discussão}

As nanopartículas obtidas via método de Stöber, utilizaram uma catálise básica na etapa de hidrólise e condensação durante sua síntese. Neste tipo de reação, ocorre uma substituição nucleofílica bimolecular do tipo SN2 no átomo metálico. O ataque nucleofílico sobre o átomo de silício pelo ânion hidróxido $\left(\mathrm{OH}^{-}\right)$, gera um intermediário penta-coordenado carregado negativamente, que em seguida sofre a perda de um ânion alcóxido $\left(\mathrm{RO}^{-}\right)$, e dá origem a um material substituído, como segue a reação química abaixo.

Hidrólise

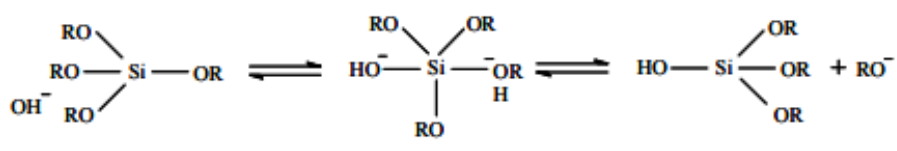

Condensaçăo

$\mathrm{RO}-\mathrm{Si}(\mathrm{OH})_{3}+\mathrm{OH}^{-} \stackrel{\text { rápida }}{\rightleftharpoons} \mathrm{RO}-\mathrm{Si}(\mathrm{OH})_{2} \mathrm{O}^{-}+\mathrm{H}_{2} \mathrm{O}$

$\mathrm{RO}-\mathrm{Si}(\mathrm{OH})_{3}+\mathrm{RO}-\mathrm{Si}(\mathrm{OH})_{2} \mathrm{O}^{-} \stackrel{\text { lenta }}{\rightleftharpoons} \mathrm{RO}-\mathrm{Si}(\mathrm{OH})_{2} \mathrm{O}-\mathrm{Si}(\mathrm{OH})_{2} \mathrm{OR}+\mathrm{OH}^{-}$
Os resultados obtidos com as análises de DLS podem ser observados na Tabela 1 e 0 espectro de infravermelho na Figura 1.

Tabela 1: Resultados de $D_{m}$ e PDI obtidos para nanopartículas de sílica dopadas e não dopadas com o complexo de lantanídeo.

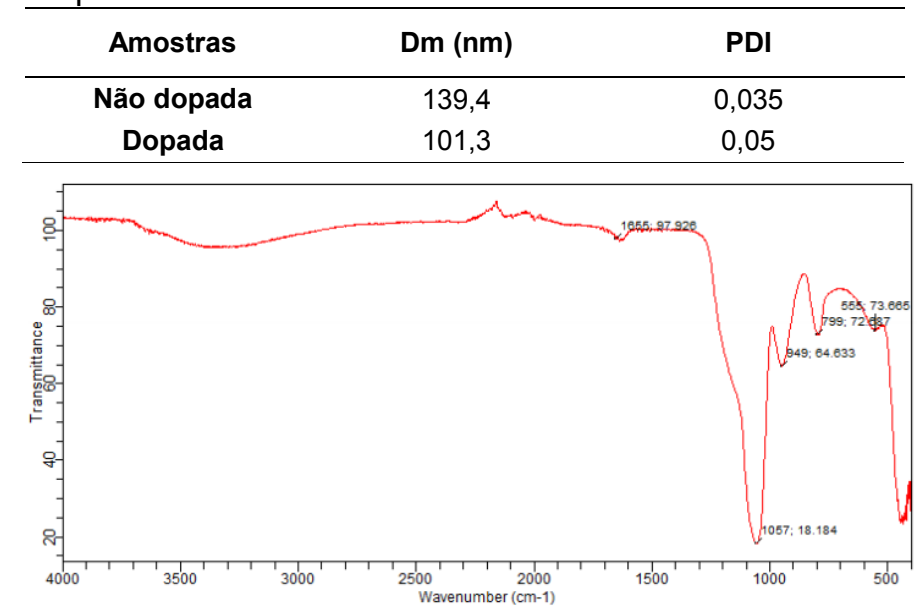

Figura 1: Espectro no infravermelho das $\mathrm{NP}-\mathrm{SiO}_{2}$.

\section{Conclusão}

O uso do método de Stöber mostrou-se eficiente para a síntese de partículas a base de sílica. Foram obtidos nanopartículas com $D_{m}$ em torno de $101,3 \mathrm{~nm}$ e PDI menor que 0,1. Espectros no infravermelho indicaram a formação de nanopartículas de sílica dado o aparecimento de modos vibracionais em 1057, 799 e 470 $\mathrm{cm}^{-1}$ característicos deste tipo de partícula.

\section{Agradecimentos}

Instituto Nacional de Ciências e Tecnologias Analíticas Avançadas (INCTAA - CNPq e FAPESP) e CNPq.

${ }^{1}$ Gaspar, R. D. L.; Jorge, H. S. K.; Mazali, I. O.; Raimundo, I. M. Jr.; Sígoli, F.

J. C. J. Chem. Plus Chem. 2015, 80, 1721. 